\title{
What incentives increase data sharing in health and medical research? A systematic review
}

\author{
Anisa Rowhani-Farid ${ }^{*}$ (D, Michelle Allen and Adrian G. Barnett
}

\begin{abstract}
Background: The foundation of health and medical research is data. Data sharing facilitates the progress of research and strengthens science. Data sharing in research is widely discussed in the literature; however, there are seemingly no evidence-based incentives that promote data sharing.

Methods: A systematic review (registration: doi.org/10.17605/OSF.IO/6PZ5E) of the health and medical research literature was used to uncover any evidence-based incentives, with pre- and post-empirical data that examined data sharing rates. We were also interested in quantifying and classifying the number of opinion pieces on the importance of incentives, the number observational studies that analysed data sharing rates and practices, and strategies aimed at increasing data sharing rates.

Results: Only one incentive (using open data badges) has been tested in health and medical research that examined data sharing rates. The number of opinion pieces $(n=85)$ out-weighed the number of article-testing strategies $(n=76)$, and the number of observational studies exceeded them both $(n=106)$.

Conclusions: Given that data is the foundation of evidence-based health and medical research, it is paradoxical that there is only one evidence-based incentive to promote data sharing. More well-designed studies are needed in order to increase the currently low rates of data sharing.
\end{abstract}

Keywords: Incentives, Data sharing, Open data, Meta-research

\section{Rationale}

Despite the current shift towards more open data in health and medical research, there are seemingly no evidence-based incentives that increase data sharing. As such, a systematic review was used to verify the lack of evidence-based incentives in this area.

\section{Objective}

This study aims to systematically review the literature to appraise and synthesise scientific research papers that concern incentives that have been tested to increase data sharing in health and medical research.

\footnotetext{
* Correspondence: anisa.rowhanifarid@hdr.qut.edu.au

Australian Centre for Health Services Innovation, Institute of Health and Biomedical Innovation, Queensland University of Technology, 60 Musk Avenue, Kelvin Grove 4059, Australia
}

(c) The Author(s). 2017 Open Access This article is distributed under the terms of the Creative Commons Attribution 4.0 International License (http://creativecommons.org/licenses/by/4.0/), which permits unrestricted use, distribution, and reproduction in any medium, provided you give appropriate credit to the original author(s) and the source, provide a link to the Creative Commons license, and indicate if changes were made. The Creative Commons Public Domain Dedication waiver (http://creativecommons.org/publicdomain/zero/1.0/) applies to the data made available in this article, unless otherwise stated.

\section{Background}

Research waste: hidden data, irreproducible research The foundation of health and medical research is data-its generation, analysis, re-analysis, verification, and sharing [1]. Data sharing is a key part of the movement towards science that is open, where data is easily accessible, intelligible, reproducible, replicable, and verifiable [2]. Data sharing is defined here as making raw research data available in an open data depository, and includes controlled access where data is made available upon request which may be required due to legal or ethical reasons. Despite the wide-scale benefits of data sharing such as addressing global public health emergencies, it is yet to become common research practice. For instance, the severe acute respiratory syndrome (SARS) disease was controlled only 4 months after its emergence by a World Health Organization-coordinated effort based on extensive data sharing [3]. Likewise, the 
researchers working on the Ebola outbreak have recently committed to work openly in outbreaks to honour the memory of their colleagues who died at the forefront of the Ebola outbreak, and to ensure that no future epidemic is as devastating [4]. Notwithstanding these benefits, numerous studies have demonstrated low rates of data sharing in health and medical research, with the leading journal the British Medical Journal (BMJ) having a rate as low as $4.5 \%$ [5] and biomedical journal articles $0 \%$ [6]. There are of course legitimate reasons to withhold data, such as the concern about patient privacy, and the requirement for patient consent for sharing [7].

With $85 \%$ of the world's spending on health and medical research, an estimated $\$ 170$ billion, wasted every year, it is clear that the scientific community is in crisis, leading to questions about the veracity of scientific knowledge [8]. Data sharing and openness in scientific research should be fundamental to the philosophy of how scientific knowledge is generated. Thomas Kuhn introduced the concept of paradigm shifts that arise from a scientific crisis. The paradigm shift before us today is from closed, hidden science to open science and data sharing [9]. Sharing scientific data will allow for data verification and re-analysis, and for testing new hypotheses. Open data reduces research waste in terms of time, costs, and participant burden, and in turn, strengthens scientific knowledge by ensuring research integrity $[5,10]$.

The many current problems in health and medical research have led to the emergence of a new field, metaresearch, which is concerned with improving research practices [2]. Meta-research has five sub-themes with 'reproducibility' and 'incentives' as two of the themes [2]. Reproducibility is concerned with the verification of research findings, which can be achieved through the sharing of data and methods [2]. Incentives is concerned with rewarding researchers, which includes incentives to share their data and methods [2]. We were interested in how researchers are incentivised to openly share their raw data, thus combining two sub-themes of meta-research.

\section{Research waste: historical barriers}

Historically, it has not been common practice for the content of a research article to include access to the raw data from scientific experiments [11]. This flaw, created by technological limitations among others, has hindered the progress of scientific knowledge [5]. However, we can no longer blame technology for outdated research practices. There are many data depositories which allow researchers to easily share their data using a citable DOI. There have also been many recent policies and frameworks to encourage openness in research [7]. Yet, uptake in health and medicine is low and what is lacking, it appears, are rewards that incentivize researchers to share their data [11]. Incentives are defined here as rewards that are given to researchers if they participate in sharing their raw scientific data [12].

\section{Research design and methodology}

The Queensland University of Technology (QUT) Library staff assisted in developing a rigorous and clearly documented methodology for both the search strategy and the selection of studies. The aim was to minimise bias by documenting the search process and the decisions made to allow the review to be reproduced and updated.

The Cochrane Handbook for Systematic Reviews was used as a guide for this systematic review: http://handbook.cochrane.org/. The EQUATOR Network Additional file 1: PRISMA (2009) Checklist [13] was used to ensure good practice as well as accurate reporting.

Three systematic review registries (Prospero, Joanna Briggs Institute, and Cochrane) were checked to ensure our proposed systematic review had not already been done. Our systematic review protocol was registered at the Open Science Framework on 1 August 2016 (doi.org/10.17605/OSF.IO/6PZ5E).

\section{Inclusion criteria \\ Types of documents}

This review considered published journal articles with empirical data that trialed any incentive to increase data sharing in health and medical research.

\section{Types of data}

Articles must have tested an incentive that could increase data sharing in health and medical research. For the purposes of this review, health and medical research data is defined as any raw data that has been generated through research from a health and medical facility, institute or organisation.

Incentives are defined here as 'a benefit, reward, or cost that motivates an [...] action'. This was based on the definition of incentives in economics, which groups incentives into four categories: financial, moral, natural, and coercive [14].

\section{Types of measures}

The review included any paper with empirical data on sharing that compared an intervention and control, which used a clear research design (including randomised and non-randomised designs). The types of measures included are the percent of datasets shared, or the number of datasets shared, or the relative ratio of data sharing.

\section{Exclusion Criteria}

This review excluded the following, but still classified these excluded papers by field: 
- all editorial and opinion pieces that only discuss strategies to increase data sharing without trialling them.

- strategies that do not involve incentives, e.g., education seminars, change in a data sharing policy or some other policy, access to data management tools and managers.

- observational studies that describe data sharing patterns.

\section{Search Strategy}

This search strategy was designed to access published articles through the following steps:

1) ((("open science" OR "open data" OR "data sharing") AND (incentive* OR motivation* OR reward* OR barrier*)))

2)

\begin{tabular}{ll}
\hline $\begin{array}{l}\text { Database Health/ } \\
\text { Medical }\end{array}$ & Search \\
PubMed & (("open science" OR "open data" OR "data sharing") \\
& AND (incentive* OR motivation* OR reward* \\
& OR barrier*)) \\
EMBASE & $($ ("open science" OR "open data" OR "data sharing") \\
& AND (incentive* OR motivation* OR reward* \\
& OR barrier*)) \\
CINAHL & (("open science" OR "open data" OR "data sharing") \\
& AND (incentive* OR motivation* OR reward* \\
& OR barrier*)) \\
Multi-disciplinary & Search \\
databases & \\
Scopus & (("open science" OR "open data" OR "data sharing") \\
& AND (incentive* OR motivation* OR reward* \\
& OR barrier*)) \\
Web of Science & (("open science" OR "open data" OR "data sharing") \\
& AND (incentive* OR motivation* OR reward* \\
& OR barrier*)) \\
\hline
\end{tabular}

3) Relevant articles that did not appear in the database search but were known to the reviewers were handpicked and extracted into EndNote.

\section{Process of selecting and evaluating articles}

Two reviewers, ARF and MA, screened the titles of the articles and based on the inclusion and exclusion criteria, extracted them into EndNote. Duplicates were removed.

The reviewers independently screened the extracted article titles and abstracts based on the inclusion and exclusion criteria and categorised them into five groups:

1) Incentives

2) Other strategies
3) Opinion pieces

4) Observational studies

5) Irrelevant

ARF read the titles and abstracts of all extracted articles and MA verified her findings by reading a random sample of 30\%. Discrepancies between the two reviewers were approximately $10 \%$, however these were relatively minor and resolved through discussion of the scope of each of the categories. For instance, a research paper outlined the introduction of a data system, one reviewer classified it as an observational study, but after discussion it was agreed that it was a strategy article as its objective was to increase data sharing rates rather than observing data sharing patterns.

\section{Process of extracting relevant information}

The two reviewers independently read eligible documents and extracted data sharing incentives in health and medical research. Both reviewers were agnostic regarding the types of incentives to look for. The final list of incentives was determined and agreed on by all authors [11].

\section{Data synthesis}

Individual incentives were grouped into research fields. A qualitative description of each incentive was presented.

Based on our prior experience of the literature, the research fields and sub-fields for classification were:

a. Health and medical research

i. Psychology

ii. Genetics

iii. Other (health/medical)

b. Non-health and medical research
i. Information technology
ii. Ecology
iii. Astronomy
iv. Other (non-health/medical)

The other article-strategies, opinion pieces, and observational studies were also grouped into the same research fields.

\section{Results}

The database searches found 1415 articles, 1039 of which met the inclusion criteria based on assessment of titles and abstracts and were exported into EndNote. After automatically removing duplicates, 670 articles remained and after manually removing the remainder of the duplicates, 586 articles remained.

586 titles and abstracts were read and categorised based on the above inclusion and exclusion criteria. One study was hand-picked as it met the inclusion criteria, bringing the total number of extracted articles to 587 . 
After screening titles and abstracts, nine articles were classified under incentives in health and medical research. These articles were then read in full, and one of them was judged as an incentive that satisfied the inclusion criteria.

The PRISMA [13] flow chart that outlines the journey of the articles from identification to inclusion is in Fig. 1. The categorisation of all 587 articles into the sub-fields and article type is in Table 1.

A review of the reference list for the one included intervention was undertaken [15]. The titles and abstracts of the full reference list of this study (23 papers) and those that cited the study ( 5 papers) were read, but none met the inclusion criteria of this systematic review.

17 articles were irrelevant, bringing the total number of screened articles to 570. The distribution of articles across type of study was similar for both health and medical research and non-health and medical research (Table 1). Observational studies were the most common type $(\mathrm{n}=106, \mathrm{n}=124)$, then opinion pieces $(n=85, n=$ $89)$, then articles testing strategies $(n=76, n=89)$, and articles testing incentives were uncommon $(n=1, n=0)$.

\section{Observational studies about data sharing in health and medical research}

These articles did not fit the inclusion criteria, but based on the abstracts they were mostly concerned with observing data sharing patterns in the health and medical research community, using quantitative and qualitative
Table 1 Categorisation of all screened articles into sub-fields and article type

\begin{tabular}{|c|c|c|c|c|c|}
\hline \multirow{2}{*}{$\begin{array}{l}\text { Research fields } \\
\text { and sub-fields }\end{array}$} & \multicolumn{5}{|l|}{ Article type } \\
\hline & Incentives & Strategies & $\begin{array}{l}\text { Opinion } \\
\text { Pieces }\end{array}$ & $\begin{array}{l}\text { Observational } \\
\text { Studies }\end{array}$ & $\begin{array}{l}\text { Total: field } \\
\text { of studies }\end{array}$ \\
\hline \multicolumn{6}{|c|}{ Health and Medical Research } \\
\hline Psychology & 1 & 2 & 4 & 1 & 8 \\
\hline Genetics & 0 & 16 & 12 & 17 & 45 \\
\hline Other & 0 & 58 & 69 & 88 & 215 \\
\hline $\begin{array}{l}\text { Total: health and } \\
\text { medical research }\end{array}$ & 1 & 76 & 85 & 106 & 268 \\
\hline \multicolumn{6}{|c|}{ Non-Health and Medical Research } \\
\hline Astronomy & 0 & 0 & 0 & 1 & 1 \\
\hline Ecology & 0 & 5 & 11 & 8 & 24 \\
\hline $\begin{array}{l}\text { Information } \\
\text { Technology }\end{array}$ & 0 & 38 & 26 & 28 & 92 \\
\hline Other & 0 & 46 & 52 & 87 & 185 \\
\hline $\begin{array}{l}\text { Total: non-health } \\
\text { and medical } \\
\text { research }\end{array}$ & 0 & 89 & 89 & 124 & 302 \\
\hline $\begin{array}{l}\text { Total: type } \\
\text { of studies }\end{array}$ & 1 & 149 & 174 & 230 & 570 \\
\hline
\end{tabular}

methods. The motivation behind these studies was often to identify the barriers and benefits to data sharing in health and medical research. For instance, Federer et al. (2015) conducted a survey to investigate the differences in experiences with and perceptions about sharing data, as

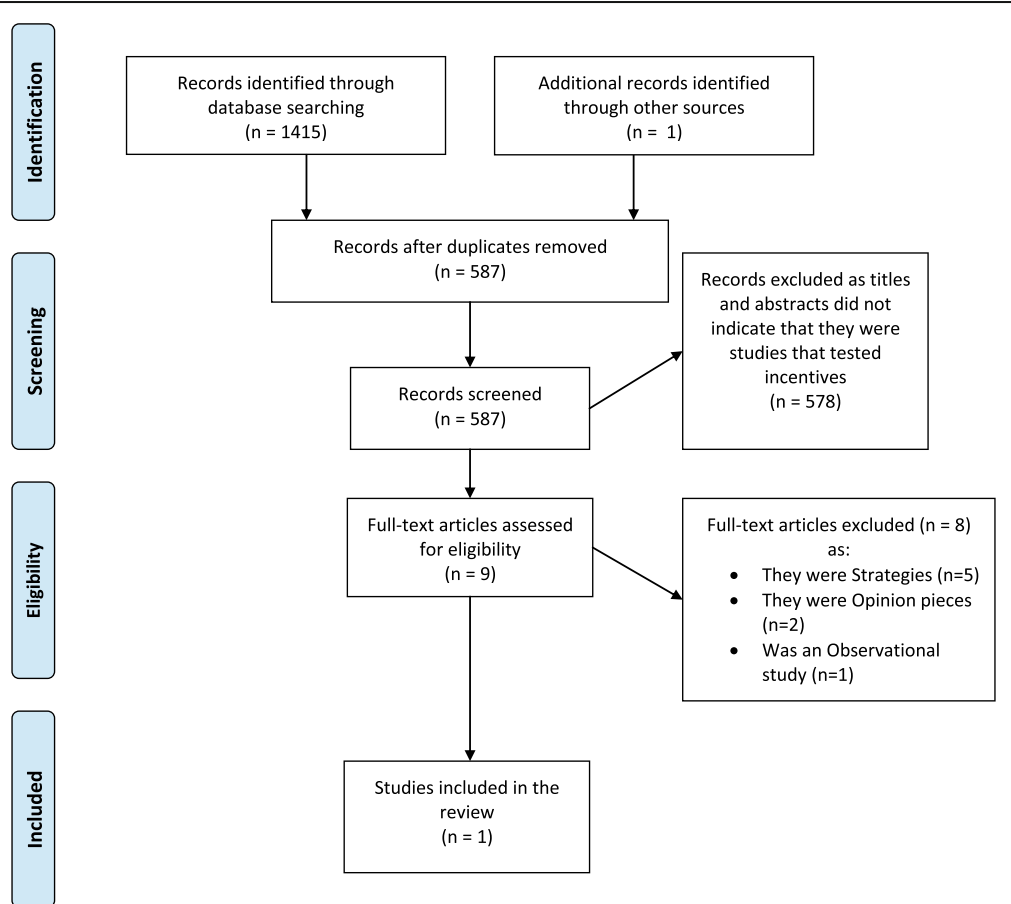

Fig. 1 PRISMA [13] Flow Chart: systematic selection of studies that have tested incentives to increase data sharing rates in health and medical research from the literature 
well as barriers to sharing among clinical and basic science researchers [16].

\section{Opinion pieces about data sharing in health and medical research}

These articles also did not fit the inclusion criteria, but based on the abstracts they were opinion and editorial pieces that discussed the importance and benefits of data sharing and also outlined the lack of incentives for researchers to share data.

\section{Main results: incentives in health and medical research Badges}

Open data and open material badges were created by the Center of Open Science and were tested at the journal Psychological Science [15]. In January 2014, the journal adopted badges to acknowledge open data, open materials and preregistration of research if published [15]. A Badges Committee at the Centre of Open Science outlined what it meant to have 'open data' and 'open materials' and the journal editorial team awarded badges to those authors who voluntarily applied for them upon article acceptance and proved that they met the criteria [15]. The criteria to earn an open data or open materials badge involved making all digitally sharable data and materials available in an open data repository [15]. Badges greatly increased the reported open data rate at the journal from $1.5 \%$ in the first half of 2012 (start point) to $39.4 \%$ in the first half of 2015 (end point) [15].

\section{Limitations}

A limitation of the badge study was that it did not use a randomized parallel group design; notwithstanding, it was the only incentive that was tested in the health and medical research community, with pre- and postincentive empirical data [15]. The pre- and post-design of the study makes it vulnerable to other policy changes over time, such as a change from a government funding agency like the recent Statement on Data Sharing from the Australian National Health and Medical Research Council [17]. However, the Kidwell et al. study addressed this concern with contemporary control journals. A limitation of the badge scheme was that even with badges, the accessibility, correctness, usability, and completeness of the shared data and materials was not $100 \%$, which was attributable to gaps in specifications for earning badges. In late 2015, the Center for Open Science Badges Committee considered provisions for situations in which the data or materials for which a badge was issued somehow disappear from public view and how adherence to badge specifications can be improved by providing easy procedures for editors/journal staff to validate data and material availability before issuing a badge, and by providing community guidelines for validation and enforcement [15].

\section{Incentives in non-health and medical research}

Of the non-health/medical incentives, seven were categorised as information technology, and nine as other. Upon reading the full text, all the 16 non-health/medical incentives were proposed incentives or strategies as opposed to tested incentives with comparative data.

\section{Strategies to increase data sharing in health and medical research}

Given that the systematic review found only one incentive, we classified the data sharing strategies tested in the health and medical research community. Seventy-six articles were classified under 'strategies' and Table 2 shows the further classification into categories based on a secondary screening of titles and abstracts. The articles are grouped by whether they presented any data, descriptive, or empirical.

The majority, 57/76, of strategies were technological strategies such as the introduction of a data system to manage and store scientific data. Seven of the 76 strategies concerned encouraging collaboration among research bodies to increase data sharing. Eight were a combination of collaboration across consortia and the introduction of a technological system. Three had a data sharing policy as the strategy but did not test the effectiveness of the policy, but two of them reported descriptive data from their experience in implementing the policy. One strategy was an open data campaign.

Below we give some examples of the strategies used to promote data sharing.

\section{Strategies in health and medical research: data systems Dataset linkage-attribution}

Two articles discussed an incentive system for human genomic data and data from rare diseases, namely, microattribution and nanopublication-the linkage of data to their contributors. However, the articles only discussed the models and did not present empirical data $[18,19]$.

Another article discussed the OpenfMRI project that aims to provide the neuroimaging community with a resource to support open sharing of fMRI data [20]. In 2013, the OpenfMRI database had 18 full datasets from seven different laboratories and in October 2016, the database had 55 datasets openly available (https://openfmri.org/dataset/). The authors identified credit as a barrier towards sharing data and so incorporated attribution into the OpenfMRI website where a dataset is linked to the publication and the list of investigators involved in collecting the data [20].

\section{Electronic laboratory notebooks}

An article discussed open source drug discovery and outlined its experience with two projects, the 
Table 2 Categorisation of the 76 data sharing strategy articles

\begin{tabular}{|c|c|c|c|}
\hline Sub-theme of health and medical research & Category (numbers) & Empirical or descriptive data & $\begin{array}{l}\text { None or little empirica } \\
\text { or descriptive data }\end{array}$ \\
\hline Psychology & $\begin{array}{l}\text { Data system } \\
\text { (2) }\end{array}$ & $2[33,34]$ & \\
\hline \multirow[t]{3}{*}{ Genetics } & Data system (14) & $12[19,35-45]$ & $2[46,47]$ \\
\hline & Collaboration and data system (1) & & $1[25]$ \\
\hline & Collaboration (1) & & $1[48]$ \\
\hline \multirow[t]{5}{*}{ Other (health and medical research) } & Data system (41) & $35[19-21,49-80]$ & $6[81-86]$ \\
\hline & Collaboration and data system ( 7 ) & $7[22,23,87-91]$ & \\
\hline & Collaboration (6) & $3[24,92,93]$ & 3 [94-96] \\
\hline & $\begin{array}{l}\text { Policy } \\
\text { (3) }\end{array}$ & $2[26,97]$ & $1[98]$ \\
\hline & $\begin{array}{l}\text { Campaign } \\
\text { (1) }\end{array}$ & & $1[27]$ \\
\hline
\end{tabular}

praziquantel (PZG) project and the Open Source Malaria project [21]. The article did not have pre- and post-strategy data. The authors discussed the constituent elements of an open research approach to drug discovery, such as the introduction of an electronic lab notebook that allows the deposition of all primary data as well as data management and coordination tools that enhances community input [21]. The article describes the benefits and successes of the open projects and outlines how their uptake needs to be incentivised in the scientific community [21].

\section{Strategies in health and medical research: collaboration and data system}

An article discussed the development of the Collaboratory for MS3D (C-MS3D), an integrated knowledge environment that unites structural biologists working in the area of mass spectrometric-based methods for the analysis of tertiary and quaternary macromolecular structures (MS3D) [22]. C-MS3D is a web-portal designed to provide collaborators with a shared work environment that integrates data storage and management with data analysis tools [22]. The goal is not only to provide a common data sharing and archiving system, but also to assist in the building of new collaborations and to spur the development of new tools and technologies [22].

\section{Attribution}

One article outlined the collaborative efforts of the Global Alzheimer's Association Interactive Network (GAAIN) to consolidate the efforts of independent Alzheimer's disease data repositories around the world with the goals of revealing more insights into the causes of Alzheimer's disease, improving treatments, and designing preventative measures that delay the onset of physical symptoms [23]. In 2016, they had registered 55 data repositories from around the world with over 25,000 subjects using GAAIN's search interfaces [23]. The methodology employed by GAAIN to motivate participants to voluntarily join its federation is by providing incentives: data collected by its data partners are advertised, as well as the identity of the data partners, including their logos and URL links, on each GAAIN search page [23]. GAIIN attributes its success in registering 55 data repositories to date to these incentives which provide opportunities for groups to increase their public visibility while retaining control of their data, making the relationship between GAIIN and its partners mutually beneficial [23]. This study did not have pre- and post-strategy empirical data, but described the importance of incentives in motivating researchers to share their data with others [23].

\section{Strategies in health and medical research: collaboration}

An article described how data sharing in computational neuroscience was fostered through a collaborative workshop that brought together experimental and theoretical neuroscientists, computer scientists, legal experts, and governmental observers [24]. This workshop guided the development of new funding to support data sharing in computational neuroscience, and considered a conceptual framework that would direct the data sharing movement in computational neuroscience [24]. The workshop also unveiled the impediments to data sharing and outlined the lack of an established mechanism to provide credit for data sharing as a concern [24]. A recommendation was that dataset usage statistics and other user feedback be used as important measures of credit [24].

One article addressed the need to facilitate a culture of responsible and effective sharing of cancer genome data through the establishment of the Global Alliance for Genomic Health (GA4GH) in 2013 [25]. The collaborative body unpacked the challenges with sharing cancer 
genomic data as well as the potential solutions [25]. The GA4GH developed an ethical and legal framework for action with the successful fostering of an international 'coalition of the willing' to deliver a powerful, globally accessible clinic-genomic platform that supports datadriven advances for patients and societies [25].

\section{Strategies in health and medical research: policy}

An article discussed the efforts of the Wellcome Trust Sanger Institute to develop and implement an institutewide data sharing policy [26]. The article outlined that successful policy implementation depends on working out detailed requirements (guidance), devoting efforts and resources to alleviate disincentives (facilitation), instituting monitoring processes (oversight), and leadership [26]. The topic of disincentives (facilitation) included concerns about lack of credit [26]. They propose that cultural barriers to data sharing continue to exist and that it is important to align the reward system to ensure that scientists sharing data are acknowledged/cited and that data sharing is credited in research assessment exercises and grant career reviews [26].

\section{Strategies in health and medical research: campaign}

One intervention was an open data campaign which was included in the review via an open letter in June 2014 from the AllTrials campaign to the director of the European Medicines Agency to remove barriers to accessing clinical trial data [27]. The AllTrials campaign is supported by more than 78,000 people and 470 organisations worldwide [27]. This letter contributed to the European Medicines Agency publishing the clinical reports underpinning market authorization requests for new drugs, which was part of a more proactive policy on transparency that applied to all centralized marketing authorisations submitted after 1 January 2015 [27]. The adoption of this policy was a significant step in ensuring transparency of health and medical research in Europe [27].

\section{Discussion}

This systematic review verified that there are few evidence-based incentives for data sharing in health and medical research. The irony is that we live in an evidence-based world, which is built upon the availability of raw data, but we hardly have any evidence to demonstrate what will motivate researchers to share data. To date, open data badges are the only tested incentive. Badges are an effective signal and incentive for open practices and journals can offer them to authors who are willing and able to meet criteria to earn an open data and open material badge [15].

It is interesting to note the great number of opinion pieces $(n=85)$ on the importance of developing incentives for researchers, which outnumbered the number of articles that tested strategies to increase data sharing rates $(n=76)$. 'Opinion pieces' are mutually exclusive from 'strategies' as the former is concerned with discussing possible strategies and incentives and the latter tests the ideas and strategies and provides evidence of what works or does not work. These strategies included: the introduction of data systems such as electronic laboratory notebooks and databases for data deposition that incorporated a system of credit through data linkage; collaboration across consortia that also introduce data systems that also use data attribution as an incentive; collaboration across consortia through workshops and development of frameworks for data sharing; implementation of data sharing policies; and campaigns to promote data sharing. These strategies discussed the requirement of introducing rewards to increase data sharing rates and the only form of incentive used was via data attribution and advertising on websites. Studies that test the effectiveness of attribution and advertising as a form of credit are necessary.

In light of the small number of studies, we see a clear need for studies to design and test incentives that would motivate researchers to share data. Organisations are promoting the development of incentives to reduce research waste. In late 2016, the Cochrane and the REWARD alliance combined to create the annual Cochrane-REWARD prize for reducing waste in research. The monetary prize is awarded to 'any person or organisation that has tested and implemented strategies to reduce waste in one of the five stages of research production [question selection, study design, research conduct, publication, and reporting] in the area of health'. This prize is an example of an incentive for researchers to design studies or implement policies that reduce research waste; it will be interesting to see the impact of this initiative [28].

Another endeavour in the area of developing incentives and rewards for researchers is the convening in early 2017 of a group of leaders from the USA and Europe from academia, government, journals, funders, and the press to help develop new models for academic promotion and professional incentives that would promote the highest quality science, organised by the Meta-Research Innovation Center at Stanford (METRICS). The focus will be on designing practical actions that embody principles that this community has embraced, while also recognizing that the effect of any such policies will need empirical evaluation.

While the systematic barriers to widespread data sharing are being addressed through the general shift towards more openness in research, the conversation on data sharing includes an alternative view where users of shared data are called 'research parasites' who 'steal from 
research productivity' and who are 'taking over' $[29,30]$. There is also some questioning of whether data sharing is worth the effort [30]. These points, however, are contrary to the purpose of sharing data, which is to progress science as a body of knowledge and to make the research process more robust and verifiable $[5,30]$.

\section{Limitations}

A limitation of this systematic review is that we did not search the grey literature (materials and research produced by organizations outside of the traditional commercial or academic publishing and distribution channels). This review could be perceived as having a narrow design, given that we anticipated a lack of evidence-based incentives for data sharing in health and medical research, hence making the topic of this systematic review too simple. However, we could not be sure that there were no incentives and the recent paper by Lund and colleagues (2016) emphasises the importance of conducting systematic reviews prior to designing interventions in order to avoid adding to the already large issue of research waste [31].

\section{Conclusions}

The current meta-research discourse outlines the numerous benefits of openness in research: verification of research findings, progressing health and medicine, gaining new insights from re-analyses, reducing research waste, increasing research value, and promoting research transparency. However, this systematic review of the literature has uncovered a lack of evidencebased incentives for researchers to share data, which is ironic in an evidence-based world. The open data badge is the only tested incentive that motivated researchers to share data [15]. This low-cost incentive could be adopted by journals and added to the reward system to promote reproducible and sharable research $[15,32]$. Other incentives like attribution require empirical data. Instead of evidence-based incentives, the literature is full of opinion pieces that emphasize the lack of incentives for researchers to share data, outweighing the number of strategies that aim to increase data sharing rates in health and medicine. Observational studies that identify data sharing patterns and barriers are also plentiful, and whilst these studies can provide useful background knowledge, they do not provide good evidence of what can be done to increase data sharing.

\section{Additional file}

Additional file 1: PRISMA (2009) Checklist. (DOC 62 kb)

\section{Abbreviations}

AGB: Adrian Gerard Barnett; ARF: Anisa Rowhani-Farid; C-MS3D: Collaboratory for MS3D; GA4GH: Global Alliance for Genomic Health; GAAIN: Global Alzheimer's Association Interactive Network; MA: Michelle Allen;

METRICS: Meta-Research Innovation Center at Stanford; PRISMA: Preferred Reporting Items for Systematic Reviews and Meta-Analyses;

PZG: Praziquantel; QUT: Queensland University of Technology;

REWARD: Reduce research Waste and Reward Diligence; WTSI: Wellcome

Trust Sanger Institute

\section{Acknowledgements}

The QUT Librarians assisted in designing the search strategy for this review.

\section{Funding}

No monetary assistance was provided for this systematic review; however, support was provided in kind by the Australian Centre for Health Services Innovation at the Institute of Health and Biomedical Innovation at QUT.

\section{Availability of data and materials}

The datasets generated and analysed during the current study are available at the Open Science Framework repository (DOI 10.17605/OSF.IO/DSPU8).

\section{Authors' contributions}

ARF collected and analysed all the data for the study and wrote the manuscript. MA collected the data and analysed (30\%) for the study and edited the manuscript. AGB provided close student mentorship for this research, which is a part of ARF's PhD under his primary supervision, and was a major contributor for the writing of this manuscript. All authors read and approved the final manuscript.

\section{Competing interests}

The authors declare that they have no competing interests.

\section{Consent for publication}

Not applicable.

\section{Ethics approval and consent to participate}

Not applicable.

\section{Publisher's Note}

Springer Nature remains neutral with regard to jurisdictional claims in published maps and institutional affiliations.

Received: 20 December 2016 Accepted: 13 April 2017

Published online: 05 May 2017

\section{References}

1. Molloy J. The Open Knowledge Foundation: Open Data Means Better Science. PLoS Biol. 2011;9(12):e1001195.

2. Ioannidis JPA, Fanelli D, Dunne DD, Goodman SN. Meta-research: Evaluation and Improvement of Research Methods and Practices. PLoS Biol. 2015; 13(10):e1002264.

3. Destro Bisol G, Anagnostou P, Capocasa M, Bencivelli S, Cerroni A, Contreras J, Enke N, Fantini B, Greco P, Heeney C, et al. Perspectives on Open Science and scientific data sharing:an interdisciplinary workshop. J Anthropol Scie. 2014;92:179-200.

4. Yozwiak N, Schaffner S, Sabeti P. Data sharing: Make outbreak research open access. Nature. 2015;518(7540):477-9.

5. Karczewski K, Tatonetti N, Manrai A, Patel C, Titus Brown C, loannidis J. METHODS TO ENSURE THE REPRODUCIBILITY OF BIOMEDICAL RESEARCH. Biocomputing. 2016;2017:117-9.

6. Iqbal SA, Wallach JD, Khoury MJ, Schully SD, loannidis JPA. Reproducible Research Practices and Transparency across the Biomedical Literature. PLoS Biol. 2016;14(1):e1002333.

7. van Panhuis WG, Paul P, Emerson C, Grefenstette J, Wilder R, Herbst AJ, Heymann D, Burke DS. A systematic review of barriers to data sharing in public health. BMC Public Health. 2014;14:1144.

8. Chalmers I, Glasziou P. Avoidable waste in the production and reporting of research evidence. Lancet. 2009;374(9683):86-9.

9. Kuhn TS. The Structure of Scientific Revolutions. London: University of Chicago Press; 1996. 
10. Salman R, Beller E, Kagan J, Hemminki E, Phillips R, Savulescu J, Macleod M, Wisely J, Chalmers I. Increasing value and reducing waste in biomedical research regulation and management. Lancet. 2014;383(9912):176-85.

11. Friesike S, Schildhauer T. Open science: Many good resolutions, very few incentives, yet. In: Incentives and Performance: Governance of Research Organizations. 2015. p. 277-89.

12. Stodden V. Reproducing Statistical Results. Annu Rev Stat Appl. 2015;2(1):1-19.

13. Moher D, Liberati A, Tetzlaff J, Altman DG: Preferred reporting items for systematic reviews and meta-analyses: the PRISMA statement. BMJ. 2009;b2535.

14. What is Economics? [http://www.whatiseconomics.org/what-is-economics/ incentives/]. Accessed 21 July 2016.

15. Kidwell MC, Lazarevi LB, Baranski E, Hardwicke TE, Piechowski S, Falkenberg L-S, Kennett C, Slowik A, Sonnleitner C, Hess-Holden C, et al. Badges to Acknowledge Open Practices: A Simple, Low-Cost, Effective Method for Increasing Transparency. PLoS Biol. 2016;14(5):e1002456.

16. Federer $L M, L u Y L$, Joubert DJ, Welsh J, Brandys B: Biomedical data sharing and reuse: Attitudes and practices of clinical and scientific research staff. PloS one. 2015;10(6):e0129506.

17. NHMRC Statement on Data Sharing [https://www.nhmrc.gov.au/grantsfunding/policy/nhmrc-statement-data-sharing]. Accessed 3 Apr 2017.

18. Patrinos GP, Cooper DN, van Mulligen E, Gkantouna V, Tzimas G, Tatum Z, Schultes $\mathrm{E}$, Roos M, Mons B. Microattribution and nanopublication as means to incentivize the placement of human genome variation data into the public domain. Hum Mutat. 2012;33(11):1503-12

19. Roos M, Schultes EA, Mons B. Speeding up research with the Semantic Web. Orphanet Journal of Rare Diseases. 2012;7.

20. Poldrack RA, Barch DM, Mitchell JP, Wager TD, Wagner AD, Devlin JT, Cumba C, Koyejo O, Milham MP. Towards open sharing of task-based fMRI data: The OpenfMRI project. Frontiers in Neuroinformatics. 2013;7:12.

21. Robertson MN, Ylioja PM, Williamson AE, Woelfle M, Robins M, Badiola KA, Willis P, Olliaro P, Wells TNC, Todd MH. Open source drug discovery - A limited tutorial. Parasitology. 2014;141(1):148-57.

22. Yu ET, Hawkins A, Kuntz ID, Rahn LA, Rothfuss A, Sale K, Young MM, Yang CL, Pancerella CM, Fabris D. The Collaboratory for MS3D: A New Cyberinfrastructure for the Structural Elucidation of Biological Macromolecules and Their Assemblies Using Mass Spectrometry-Based Approaches. J Proteome Res. 2008;7(11):4848-57.

23. Toga AW, Neu SC, Bhatt P, Crawford KL, Ashish N. The Global Alzheimer's Association Interactive Network. Alzheimer's Dement. 2016;12(1):49-54.

24. Teeters $\mathrm{J}$, Harris KD, Millman KJ, Olshausen BA, Sommer FT. Data sharing for computational neuroscience. Neuroinformatics. 2008;6(1):47-55.

25. Siu LL, Lawler M, Haussler D, Knoppers BM, Lewin J, Vis DJ, Liao RG, Andre F, Banks I, Barrett JC, et al. Facilitating a culture of responsible and effective sharing of cancer genome data. Nat Med. 2016;22(5):464-71.

26. Dyke SOM, Hubbard TJP. Developing and implementing an institute-wide data sharing policy. Genome Medicine. 2011;3(9):60.

27. Goldacre B, Godlee F, Heneghan C, Tovey D, Lehman R, Chalmers I, Barbour $\checkmark$, Brown T. OPEN DATA CAMPAIGN Open letter: European Medicines Agency should remove barriers to access clinical trial data. Bmj-British Medical Journal. 2014;93768.

28. The Cochrane-REWARD prize for reducing waste in research [http://www.cochrane. org/news/cochrane-announces-cochrane-reward-prize-reducing-waste-research]. Accessed 12 Dec 2016

29. Longo DL, Drazen JM. Data Sharing. N Engl J Med. 2016:374(3):276-7.

30. Strom BL, Buyse ME, Hughes J, Knoppers BM. Data Sharing — Is the Juice Worth the Squeeze? N Engl J Med. 2016;375(17):1608-9.

31. Lund $H$, Brunnhuber $K$, Juhl C, Robinson K, Leenaars M, Dorch BF, Jamtvedt G, Nortvedt MW, Christensen R, Chalmers I. Towards evidence based research. BMJ. 2016;;5440.

32. Ioannidis JA, Khoury MJ. Assessing value in biomedical research: The pqrst of appraisal and reward. JAMA. 2014:312(5):483-4.

33. Wang L, Kogan A, Cobia D, Alpert K, Kolasny A, Miller MI, Marcus D. Northwestern University Schizophrenia Data and Software Tool (NUSDAST). Frontiers in Neuroinformatics0. 2013;7:25.

34. Wang L, Alpert $K$, Calhoun V, Keator D, King M, Kogan A, Landis D, Tallis M, Potkin SG, Turner JA, et al. Schizconnect: A one-stop web-based resource for large-scale schizophrenia neuroimaging data integration. Schizophr Bull. 2015;41:S279.

35. Choquet $R$, Fonjallaz Y, De Carrara A, Maaroufi M, Vandenbussche PY, Dhombres F, Landais P. Coding rare diseases in health information systems:
A tool for visualizing classifications and integrating phenotypic and genetic data. In: CEUR Workshop Proceedings. 2014. p. 198-203.

36. Adamusiak T, Parkinson H, Muilu J, Roos E, van der Velde KJ, Thorisson GA, Byrne M, Pang C, Gollapudi S, Ferretti V, et al. Observ-OM and Observ-TAB: Universal Syntax Solutions for the Integration, Search, and Exchange of Phenotype And Genotype Information. Hum Mutat. 2012;33(5):867-73.

37. Bartsch $\mathrm{H}$, Thompson WK, Jernigan TL, Dale AM: A web-portal for interactive data exploration, visualization, and hypothesis testing. Frontiers in Neuroinformatics. 2014;8.

38. Choquet $R$, Maaroufi M, Fonjallaz $Y$, de Carrara A, Vandenbussche PY, Dhombres F, Landais P. LORD: a phenotype-genotype semantically integrated biomedical data tool to support rare disease diagnosis coding in health information systems. AMIA Annu Symp Proc. 2015;2015:434-40.

39. Falkner JA, Hill JA, Andrews PC. Proteomics FASTA archive and reference resource. Proteomics. 2008:8(9):1756-7.

40. Kanterakis A, Kuiper J, Potamias G, Swertz MA: PyPedia. Using the wiki paradigm as crowd sourcing environment for bioinformatics protocols. Source Code for Biology and Medicine. 2015;10(1):14.

41. Queralt-Rosinach N, Pinero J, Bravo A, Sanz F, Furlong LI. DisGeNET-RDF: harnessing the innovative power of the Semantic Web to explore the genetic basis of diseases. Bioinformatics (Oxford, England). 2016:32(14):2236-8.

42. Tan A, Tripp B, Daley D. BRISK-research-oriented storage kit for biologyrelated data. Bioinformatics. 2011:27(17):2422-5.

43. Thomas DG, Gaheen S, Harper SL, Fritts M, Klaessig F, Hahn-Dantona E, Paik D, Pan S, Stafford GA, Freund ET et al: ISA-TAB-Nano: A Specification for Sharing Nanomaterial Research Data in Spreadsheet-based Format. BMC Biotechnology. 2013;13:2.

44. van Kampen AH, van Schaik BD, Pauws E, Michiels EM, Ruijter JM, Caron HN Versteeg R, Heisterkamp SH, Leunissen JA, Baas F, et al. USAGE: a web-based approach towards the analysis of SAGE data. Serial Analysis of Gene Expression. Bioinformatics. 2000;16(10):899-905.

45. Voegele C, Bouchereau B, Robinot N, McKay J, Damiecki P, Alteyrac L. A universal open-source Electronic Laboratory Notebook. Bioinformatics. 2013;29(13):1710-2.

46. Postman J, Hummer K, Bretting P, Kinard G, Bohning M, Emberland G Sinnott Q, Cyr P, Millard M, Gardner C, et al. GRIN-Global: An international project to develop a global plant genebank information management system. In: Acta Horticulturae 859. 2010. p. 49-56.

47. Kawaguchi A, Mondal A, Montesdeoca N, Govind S, Lee MJ. PADMA database: Pathogen associated drosophila microarray database. In: ICC2009 - International Conference of Computing in Engineering, Science and Information. 2009. p. 63-6.

48. Lawler M, Siu LL, Rehm HL, Chanock SJ, Alterovitz G, Burn J, Calvo F, Lacombe D, Teh BT, North KN, et al. All the World's a Stage: Facilitating Discovery Science and Improved Cancer Care through the Global Alliance for Genomics and Health. Cancer Discov. 2015;5(11):1133-6.

49. Ye S, Makedon F, Steinberg T, Shen L, Ford J, Wang Y, Zhao Y, Kapidakis S. SCENS: A system for the mediated sharing of sensitive data. In: Proceedings of the ACM/IEEE Joint Conference on Digital Libraries. 2003. p. 263-5.

50. Weinberg M, Waterman S, Lucas CA, Falcon VC, Morales PK, Lopez LA, Peter C, Gutierrez AE, Gonzalez ER, Flisser A, et al. The US-Mexico border infectious disease surveillance project: Establishing binational border surveillance. Emerg Infect Dis. 2003;9(1):97-102.

51. Tian L, Zhang W, Wang H, Wu C, Ni Y, Cao F, Yu Y. MeDetect: Domain entity annotation in biomedical references using linked open data. In: CEUR Workshop Proceedings. 2012. p. 117-20.

52. Tardif $C L$, Schäfer $A$, Trampel R, Villringer A, Turner R, Bazin PL. Open Science CBS Neuroimaging Repository: Sharing ultra-high-field MR images of the brain. Neuroimage. 2016;124:1143-8.

53. Sonne T, Jensen MM. Race by hearts: Using technology to facilitate enjoyable and social workouts. In: Lecture Notes in Computer Science (including subseries Lecture Notes in Artificial Intelligence and Lecture Notes in Bioinformatics). 2014. p. 125-32. 8770.

54. Shirts BH, Hauser RG, Bennett S, Jackson B. Using a database/repository structure to facilitate multi-institution utilization management data sharing. Am J Clin Pathol. 2013:140:A072.

55. Reilent E, Kuusik A, Puju M. Real-time data streaming for functionally improved eHealth solutions. In: Proceedings - IEEE-EMBS International Conference on Biomedical and Health Informatics: Global Grand Challenge of Health Informatics. 2012. p. 140-3. BHI 2012.

56. Redfield C, Fisher J, Horng S, Schoenfeld D, Mottley L, Wolfe RE, Salvia JN, Nathanson LA. Real-time clinical information exchange between EMS and the emergency department. Acad Emerg Med. 2013;20(5):S144-5. 
57. Peeples MM, lyer AK, Cohen JL. Integration of a mobile-integrated therapy with electronic health records: Lessons learned. J Diabetes Sci Technol. 2013;7(3):602-11.

58. Patel V, Dinov ID, Van Horn JD, Thompson PM, Toga AW. LONI MiND: Metadata in NIfTI for DWI. Neuroimage. 2010;51(2):665-76.

59. Owolabi K, Sonoiki D, Salet F, Gignac N. Application of FOSS4G and open data to support polio eradication, vaccine delivery and ebola emergency response in West Africa. Int J Geoinformatics. 2015;11(3):31-6.

60. Ocampo JM, Smart JC, Allston A, Bhattacharjee R, Boggavarapu S, Carter S, Castel AD, Collmann J, Flynn C, Hamp A, et al. Improving HIV Surveillance Data for Public Health Action in Washington, DC: A Novel Multiorganizational DataSharing Method. JMIR Public Health Surveill. 2016;2(1):e3.

61. Natter MD, Quan J, Ortiz DM, Bousvaros A, Ilowite NT, Inman CJ, Marsolo K, McMurry AJ, Sandborg Cl, Schanberg LE, et al. An i2b2-based, generalizable, open source, self-scaling chronic disease registry. J Am Med Inform Assoc. 2013;20(1):172-9.

62. McCusker JP, Lebo T, Krauthammer M, McGuinness DL. Next generation cancer data discovery, access, and integration using Prizms and nanopublications. In: Lecture Notes in Computer Science (including subseries Lecture Notes in Artificial Intelligence and Lecture Notes in Bioinformatics). 2013. p. 105-12. 7970 LNBI.

63. Lozano-Rubi R, Pastor X, Lozano E. OWLing Clinical Data Repositories With the Ontology Web Language. JMIR Med Inform. 2014;2(2):e14.

64. Lefort L, Leroux H. Design and generation of linked clinical data cubes. In: CEUR Workshop Proceedings. 2013.

65. Kazansky Y, Wood D, Sutherlun J. The current and potential role of satellite remote sensing in the campaign against malaria. Acta Astronaut. 2016;121: 292-305.

66. Jupp S, Malone J, Bolleman J, Brandizi M, Davies M, Garcia L, Gaulton A, Gehant S, Laibe C, Redaschi N, et al. The EBI RDF platform: Linked open data for the life sciences. Bioinformatics. 2014;30(9):1338-9.

67. Izzo M, Mortola F, Arnulfo G, Fato MM, Varesio L. A digital repository with an extensible data model for biobanking and genomic analysis management. BMC Genomics. 2014;15 Suppl 3:S3.

68. Howell FW, Cannon RC, Goddard NH. Catalyzer: A novel tool for integrating, managing and publishing heterogeneous bioscience data. Concurrency Computation Pract Experience. 2007;19(2):207-21.

69. Haselgrove C, Poline JB, Kennedy DN: A simple tool for neuroimaging data sharing. Frontiers in Neuroinformatics. 2014;8:59.

70. Fraser HSF, Habib A, Goodrich M, Thomas D, Blaya JA, Fils-Aime JR, Jazayer D, Seaton M, Khan AJ, Choi SS, et al. E-Health systems for management of MDR-TB in resource-poor environments: A decade of experience and recommendations for future work. In: Studies in Health Technology and Informatics. 2013. p. 627-31. 2013.

71. Fonseca CG, Backhaus M, Bluemke DA, Britten RD, Chung JD, Cowan BR, Dinov ID, Finn JP, Hunter PJ, Kadish AH, et al. The Cardiac Atlas Project-an imaging database for computational modeling and statistical atlases of the heart. Bioinformatics. 2011;27(16):2288-95.

72. Embi PJ, Stephens W, Myslinski R. American college of rheumatology's rheumatology informatics system for effectiveness registry pilot. Arthritis Rheum. 2013;65:S83.

73. Embi PJ, Barnes I, Myslinski R, Ervin D, Stevens W, Borlawsky T, Payne PRO. The rheumatology informatics system for effectiveness (RISE): Enabling data access across disparate sites for quality improvement and research. Arthritis Rheum. 2012;64:S1101-2.

74. Craddock C. The preprocessed connectomes project: An open science repository of preprocessed data. Biol Psychiatry. 2016;79(9):397S

75. Costa RS, Veríssimo A, Vinga S. KiMoSys: A web-based repository of experimental data for KInetic MOdels of biological SYStems. BMC Systems Biology. 2014;8(1):85

76. Coakley MF, Hurt DE, Weber N, Mtingwa M, Fincher EC, Alekseyev V, Chen DT, Yun A, Gizaw M, Swan J, et al. The NIH 3D Print Exchange: A Public Resource for Bioscientific and Biomedical 3D Prints. 3d Printing Addit Manuf. 2014;1(3):137-40.

77. Bryar JM, Dalby CK, Anastas S, Brady L, Hassett MJ, Shulman LN, Jacobson JO. Implementation of chemotherapy treatment plans (CTP) in a large comprehensive cancer center (CCC): The key roles of infrastructure and data sharing. Journal of Clinical Oncology. 2013;31(31):51.

78. Barbarito F, Pinciroli F, Mason J, Marceglia S, Mazzola L, Bonacina S. Implementing standards for the interoperability among healthcare providers in the public regionalized Healthcare Information System of the Lombardy Region. J Biomed Inform. 2012;45(4):736-45.

79. Ancker JS, Silver M, Kaushal R. Rapid growth in use of personal health records in New York, 2012-2013. J Gen Intern Med. 2014;29(6):850-4.

80. Software breakthrough makes data sharing easy. Hospital peer review. 1996; 21(11):147-150.

81. Yuanqing T, Xuesong L, Jijiao F, Xiuming W. Preventing, controlling, and sharing data of arsenicosis in China. Data Sci J. 2007;6(SUPPL):S511-7.

82. Vreeman DJ, Richoz C. Possibilities and Implications of Using the ICF and Other Vocabulary Standards in Electronic Health Records. Physiother Res Int. 2015:20(4):210-9.

83. Van Horn JD, Grethe JS, Kostelec P, Woodward JB, Aslam JA, Rus D, Rockmore D, Gazzaniga MS. The Functional Magnetic Resonance Imaging Data Center (fMRIDC): The challenges and rewards of large-scale databasing of neuroimaging studies. Philos Trans R Soc B. 2001:356(1412):1323-39.

84. Stärk KD, Arroyo Kuribreña M, Dauphin G, Vokaty S, Ward MP, Wieland B, Lindberg A. One Health surveillance - More than a buzz word? Prev Vet Med. 2015;120(1):124-30.

85. Herrick R, Horton W, Olsen T, McKay M, Archie KA, Marcus DS. XNAT Central: Open sourcing imaging research data. Neuroimage. 2016;124:1093-6.

86. Rautenberg PL, Wachtler T. Flexible specification of data models for neuroscience databases. In: Proceedings - International Workshop on Database and Expert Systems Applications, DEXA. 2011. p. 75-8. 2011.

87. Ballard DJ, Nicewander D, Skinner C. Health care provider quality improvement organization Medicare data-sharing: a diabetes quality improvement initiative. Proceedings/AMIA Annual Symposium AMIA Symposium. 2002;22-25.

88. Toga AW, Neu S, Crawford K, Bhatt P, Ashish N. The global Alzheimer's association interactive network (GAAIN). Alzheimer's Dement. 2015;11(7):121.

89. Duhaime AC, Hotz GA, Wittkampf F, Haire SW, Costine BA. Pediatric patients in the track TBI trial-testing common data elements in children. J Neurotrauma. 2014;31(12):A67.

90. Dekker A, Wiessler W, Xiao Y, Krishnapuram B, Rao B, O'Meara E, Velazquez E, Galvin J, Curran W, Lambin P. Rapid learning in practice: Validation of an EU population-based prediction model in USA trial data for H\&N cancer. Radiother Oncol. 2012;103:S229.

91. Chaudhary O. Developing the foundation for syndromic surveillance and health information exchange for yolo county, california. Online journal of public health informatics. 2012:4(2).

92. National Research Council Board on Research D, Information. The National Academies Collection: Reports funded by National Institutes of Health. In: Uhlir PF, editor. Designing the Microbial Research Commons: Proceedings of an International Symposium. Washington: National Academies Press (US) National Academy of Sciences; 2011.

93. Wong DF, Innis R, Sung LM, Gold L, Paul S, Phan P, Grant S, Manji H. New models of open innovation to rejuvenate the biopharmaceutical ecosystem a proposal by the ACNP liaison committee. Neuropsychopharmacology. 2013:38:S17.

94. Steckler T, Brose K, Haas M, Kas MJ, Koustova E, Bespalov A, Networ EPDF. The preclinical data forum network: A new ECNP initiative to improve data quality and robustness for (preclinical) neuroscience. Eur Neuropsychopharmacol. 2015;25(10):1803-7.

95. Poline JB, Breeze JL, Ghosh S, Gorgolewski KF, Halchenko YO, Hanke M, Helmer KG, Marcus DS, Poldrack RA, Schwartz $Y$ et al. Data sharing in neuroimaging research. Frontiers in Neuroinformatics. 2012;6.

96. Sharing data with physicians helps break down barriers. Data strategies \& benchmarks : the monthly advisory for health care executives. 2002;6(5):70-75.

97. Cherico-Hsii S, Bankoski A, Singal P, Horon I, Beane E, Casey M, Rebbert-Franklin $\mathrm{K}$, Sharfstein J. Sharing overdose data across state agencies to inform public health strategies: A case study. Public Health Rep. 2016;131(2):258-63.

98. IMPACT. Act levels the playing field on healthcare performance. Hosp Case Manag. 2015;23(12):156-8. 